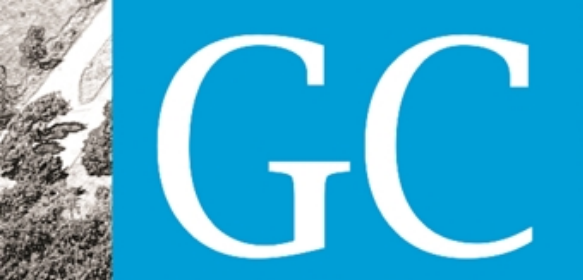

Revista Nacional de

Gerenciamento de Cidades

National Journal of Cities Management

\title{
Desigualdade estruturante, política urbana e novos agentes na produção do espaço
}

Structural inequality, urban policy and new agents in the production of the territory

Desigualdad estructural, política urbana y nuevos agentes en la producción del espacio

Letícia Pacheco dos Passos Claro

Mestranda, PPGDSCI CEAM- UnB, Brasil

leticiaclaro@hotmail.com 


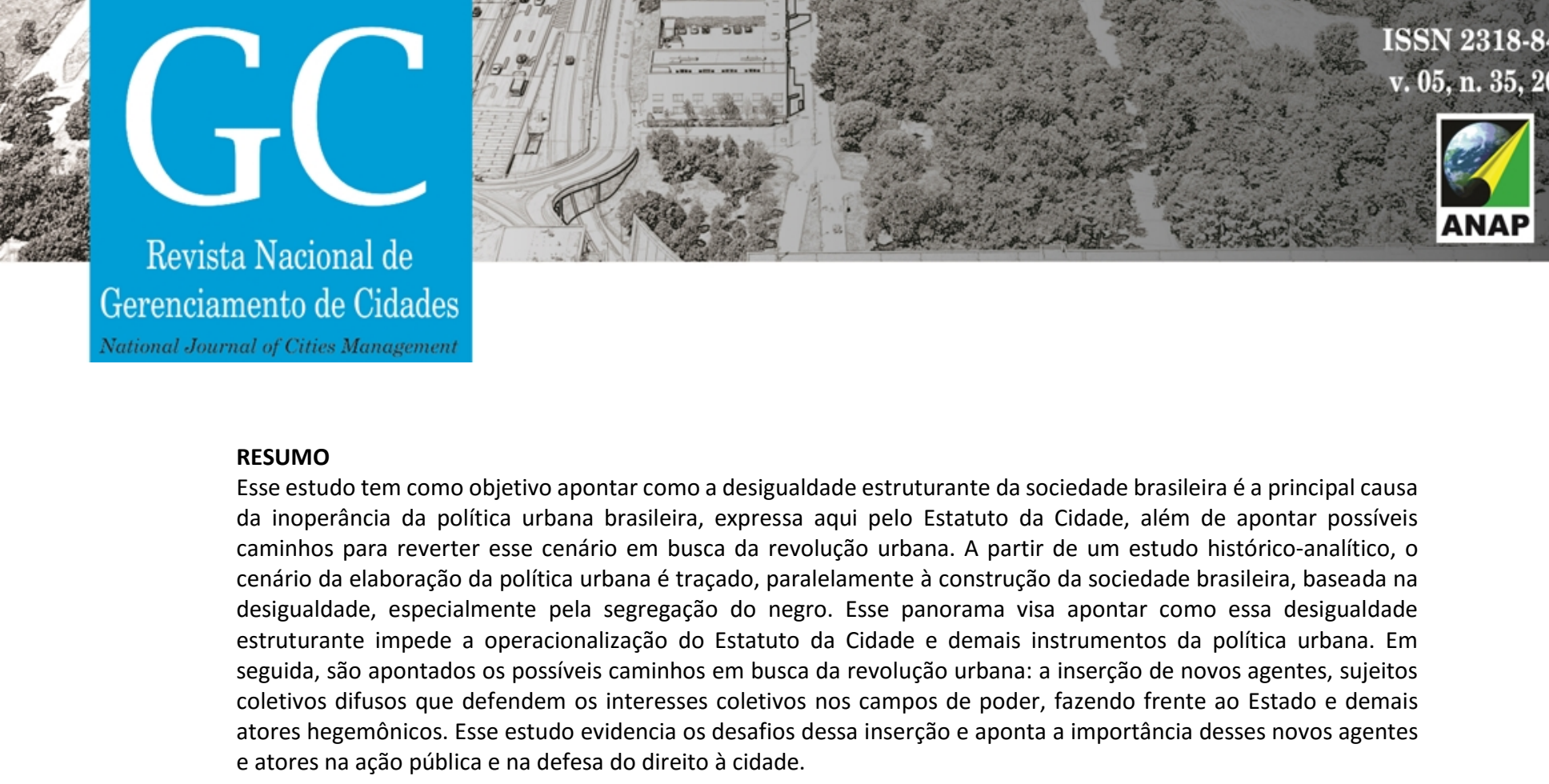

RESUMO caminhos para reverter esse cenário em busca da revolução urbana. A partir de um estudo histórico-analítico, o eira, baseada na Esse panorama visa apontar como essa desigualdade seguida, são apontados os possíveis caminhos em busca da revolução urbana: a inserção de novos agentes, sujeitos coletivos difusos que defendem os interesses coletivos nos campos de poder, fazendo frente ao Estado e demais .

PALAVRAS-CHAVE: política urbana, desigualdade, agentes

\section{ABSTRACT}

This study aims to show how the structural inequality of Brazilian society is the main cause of the inoperability of Brazilian urban policy, expressed here by the City Statute, as well as pointing out possible ways to reverse this scenario in search of the urban revolution. Based on a historical-analytical study, the scenario of the elaboration of the urban policy is traced, parallel to the construction of the Brazilian society, based on the inequality, especially by the segregation of black people. This panorama aims to point out how this structural inequality blocks the operationalization of the City Statute and other urban policy instruments. Subsequently, the possible paths in search of the urban revolution are pointed: the insertion of new agents, diffuse collective subjects who defend collective interests in the fields of power, facing the State and other hegemonic actors. This study highlights the challenges of this insertion and points out the importance of these new agents and actors in public action and in defense of the right to the city.

KEY-WORDS: urban policy, inequality, agents

\section{RESUMEN}

Este estudio tiene como objetivo apuntar cómo la desigualdad estructurante de la sociedad brasileña es la principal causa de la inoperancia de la política urbana brasileña, expresada aquí por el Estatuto de la Ciudad, además de apuntar posibles caminos para revertir ese escenario en busca de la revolución urbana. A partir de un estudio histórico-analítico, el escenario de la elaboración de la política urbana es trazado, paralelamente a la construcción de la sociedad brasileña, basada en la desigualdad, especialmente por la segregación del negro. Este panorama objetivo señalar cómo esa desigualdad estructurante impide la operacionalización del Estatuto de la Ciudad y demás instrumentos de la política urbana. En seguida se apuntan los posibles caminos en busca de la revolución urbana: la inserción de nuevos agentes, sujetos colectivos difusos que defienden los intereses colectivos en los campos de poder, haciendo frente al Estado y demás actores hegemónicos. Este estudio evidencia los desafíos de esa inserción y apunta la importancia de estos nuevos agentes y actores en la acción pública y en la defensa del derecho a la ciudad.

PALABRAS CLAVE: política urbana, desigualdad, agentes 






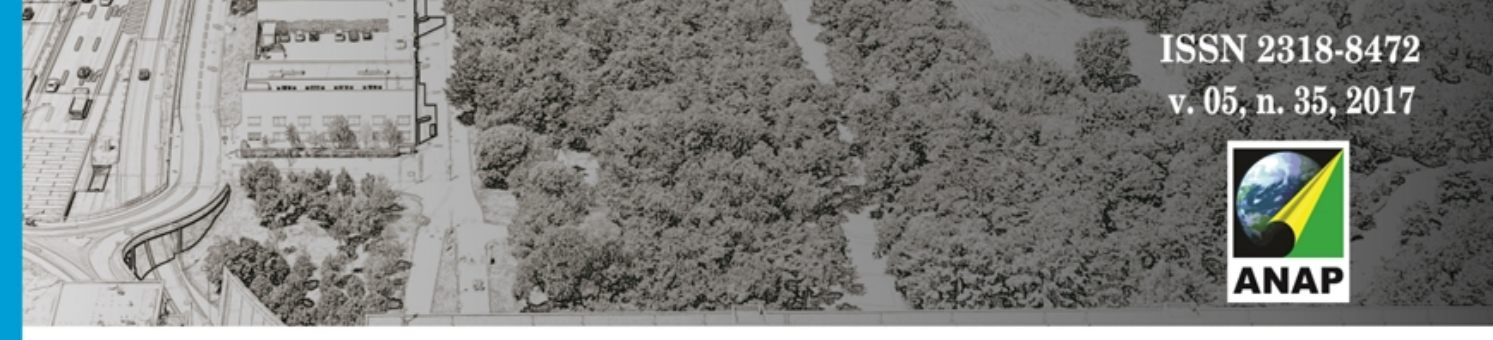

Gerenciamento de Cidades

hegemônicos). Pensar a efetividade do Estatuto da Cidade parte da reflexão desses grupos sobre a estrutura social, política e espacial das cidades brasileiras e de formas de se produzir cidades mais democráticas.

A ação desses novos atores nas cidades já representa importantes passos na produção de espaços mais democráticos. Estes atores movimentam diferentes causas e reivindicam uma cidade que vai além da estrutura de produção capitalista, reivindicam cidades mais justas, sustentáveis, ecológicas, culturais e com maior qualidade de vida. E o fazem desde por meio de ações pontuais independentes, até pela cooperação de redes de atores em escalas maiores.

A nova discussão do fazer público aos poucos substitui o termo políticas públicas por ação pública. Lascoumes e Le Gales (2012) afirmam que o modelo clássico de elaboração de políticas públicas somente pelo Estado vem cedendo lugar às interações entre atores públicos e privados, instituições financeiras, organizações não governamentais e etc.

É a utilização do território por estes atores que desenham o campo da ação pública. Lascoumes e Le Gales apontam também a governança como importante instrumento de coordenação de atores e além da criação de canais de diálogos com o Estado como ferramenta de construção coletiva dessa governança. A gestão social é um importante instrumento nessa construção coletiva, defendendo a horizontalidade de decisões, cooperação entre atores e redes, organização sistemática e maior diálogo com o Estado.

A efetivação das políticas urbanas em prol de cidades democráticas parte, essencialmente, da inserção de novos atores políticos nos campos de poder. Pela cooperação entre esses atores que lutam por objetivos comuns que está o caminho para políticas mais efetivas e contextualizadas. Maria da Glória Gohn (2000) afirma que o tradicional paradigma marxista dos movimentos sociais não se faz suficiente para compreender o contexto atual, segundo a autora, os Novos Movimentos Sociais se formam a partir de características como: a construção de um modelo teórico pautado na cultura, a compreensão da insuficiência da teoria marxista para explicar a ação individual e coletiva da sociedade contemporânea, negação do sujeito histórico redutor da humanidade, centralidade e redefinição da política e ação e identidade coletiva construída no processo.

O paradigma dos Novos Movimentos Sociais, segundo Gohn (2000), apresenta um importante personagem a ser inserido nos campos de poder: o sujeito coletivo difuso. Ainda segundo a autora, esses novos movimentos, que estão mais preocupados em assegurar direitos sociais, se utilizam de instrumentos como a mídia e atividades de protesto para atrair a opinião pública e fazer pressão contra o Estado. Além disso, os movimentos, ao negar o sujeito histórico redutor da humanidade, se organizam por estruturas descentralizadas, sem hierarquias, participativas e fluidas. Nesse contexto, as lideranças existem, mas não são personificadas, são apreendidas e explicitadas nas ações dos grupos e das correntes de opiniões.

É essa fluidez e pluralidade que constrói o sujeito coletivo difuso. É aquele que não tem cara, é a realização de do processo de identidade de grupo e que vai ser expresso nos discursos e na manifestação de diferentes grupos. A ação coletiva é formada também pelo sujeito coletivo 



